\title{
The Prevalence of ASTRAZENECA COVID Vaccine Side Effects among Nigist Elleni Mohamed Memorial Specialized Hospital Health Workers: Cross Sectional Survey
}

\author{
Gelana Garoma ${ }^{1}$, Habtamu Tamrat ${ }^{1}$, Tewoderos Shitemaw ${ }^{2}$ and Mitiku Desalegn ${ }^{1 *}$ \\ ${ }^{1}$ Department of dentistry, College of Medicine and Health Science, Wachemo University, Hosanna, Ethiopia \\ ${ }^{1}$ Department of Orthopedics, College of Medicine and Health Science, Wachemo University, Hosanna, Ethiopia \\ ${ }^{2}$ Department of Anesthesia, Menelik II Collage of Medical \& Health Science, Kotebe Metropolitan University, Addis Ababa, Ethiopia
} ${ }^{*}$ Corresponding author: Mitiku Desalegn (MSc), Department of Anesthesia, Wachemo University, college of Medicine and health science, Hossana, Ethiopia Received: October 14, 2021; Accepted: November 29, 2021; Published: November 30, 2021

\begin{abstract}
Background: The best way to eradicate COVID 19 viral infection is mass vaccination. Many studies demonstrate vaccination is associated with some local and systemic side effects. This study aimed to provide evidence on ASTRAZENECA COVID vaccine side effects.

Method: Institutional based cross-sectional survey was conducted among 254 health workers at Nigist Elleni Mohamed Memorial Specialized Hospital (NEMMSH) from July 01/2021 to August 30/2021. Data were collected consecutively through self-administered online survey created on Google Forms of platform which had been randomly delivered via (Facebook or telegram pages). Demographic data of participants, side effect after first and second dose of vaccine were covered.

Result: The prevalence of at least one side effect after first dose was $91.3 \%$ and after second dose was $67 \%$. Injection site pain (63.8\% vs. 50.4\%), headache ( $48.8 \%$ vs. $33.5 \%)$, fever ( $38.8 \%$ vs. $20.9 \%)$, muscle pain ( $38.8 \%$ vs. $21.7 \%)$, fatigue ( $26 \%$ vs. $28.7 \%$, tenderness at the site $(27.6 \%$ vs. $21.7 \%)$, and joint pain (27.6\% vs. $20.9 \%$ ) were the most commonly reported side effects after first and second dose vaccine respectively. Most of participants reported that their symptoms emerged after $6 \mathrm{~h}$ of vaccination and only less than $5 \%$ of participant's symptoms lasted more than $72 \mathrm{~h}$ of post vaccination. The younger age ( $\leq 29$ year) were more susceptible to at least one side effect $(\chi 2=4.2 ; \mathrm{p}=0.04)$ after first dose.
\end{abstract}

Conclusion: The prevalence of side effect after first and second dose vaccine was higher. Most of the symptoms were short lived and mild. This result might help to solve an emerging public health challenge (vaccine hesitancy) nurtured by misinformation related to vaccines safety.

Keywords: ASTRAZENECA COVID vaccine, Side effect, Wachemo University, Cross sectional study

\section{Introduction}

Corona viruses are single stranded RNA viruses that cause upper respiratory tract infection [1]. A clinical specimen from a patient having severe acute respiratory syndrome identified a novel coronal virus and named severe acute respiratory syndrome (SARS-CoV-2) [2].

The principal way for transmission of SARS-COVID 19 virus the exposure of the host to respiratory fluid containing the virus primarily Inhalation of air carrying virus, Deposition of virus onto exposed mucous membranes and touching surface exposed to respiratory fluid containing the virus [3].

Pathogenesis of COVID 19 begins when glycoprotein spike on the surface of the virus binds with ACE receptor of host cell [4]. After binding the viral particle get access to host cell through endocytosis [5]. The fused viral genome carries out a series enzymatic process transported by Golgi vesicles to the cell membrane and released into the extracellular space through exocytosis [6].

Multiple genomic sequence of the virus has made the development of effective vaccine to be limited [7]. 259 vaccine trials are proceeding from November 11, 2020 and the lack of effective vaccine has cost many lives. Several vaccines are developed from numerous trials, from those vaccine one of the vaccine made by ASTRAZENECA COVID vaccine [8].

COVID-19 Vaccine AstraZeneca is indicated for active immunisation to prevent COVID-19 caused by SARS-CoV-2, in individual's $\geq 18$ years old. The Vaccine AstraZeneca is a monovalent vaccine composed of a single recombinant, replication-deficient chimpanzee adenovirus (ChAdOx1) vector encoding the Sglycoprotein of SARS-CoV-2. Following administration, the $S$ glycoprotein of SARS-CoV-2 is expressed locally stimulating neutralising antibody and cellular immune responses [9]. 
COVID-19 Vaccine AstraZeneca has been assessed based on an short-term analysis of pooled data from four on-going randomised, blinded, controlled trials: a Phase I/II Study, COV001, in healthy adults 18 to 55 years of age in the UK; a Phase II/III Study, COV002, in adults $\geq 18$ years of age (including the elderly) in the UK; a Phase III Study, COV003, in adults $\geq 18$ years of age (including the elderly) in Brazil; and a Phase I/II study, COV005, in adults aged 18 to 65 years of age in South Africa [9].

The vaccination course consists of two separate doses of $0.5 \mathrm{ml}$ each. The second dose should be administered between 4 and 12 weeks after the first dose. Individuals who have taken the first dose of COVID-19 Vaccine AstraZeneca should receive the second dose of the same vaccine to complete the vaccination course. The most frequently reported adverse reactions were injection site tenderness injection site pain, headache, fatigue, myalgia, malaise [10].

Vaccine Hesitancy (VH) refers to the "delay in acceptance or refusal of vaccines despite availability of vaccine services"; it is an emerging public health challenge nourished by misinformation related to vaccines effectiveness and safety [11]. This finding was supported in the context of COVID-19 vaccines, because a fear of side effects was the most prominent reason to decrease the readiness of healthcare workers and students in Poland to accept the vaccination [12]. Published data to support adverse reaction of ASTRAZENECA COVID-19 vaccine are lacking which is a driver of vaccine hesitancy. The knowledge about what happens post vaccination in the actual world among the general population is still modest, thus, by describing what to expect after 1st and 2nd dose of vaccination will help in lowering the apprehension about this type vaccines, increased the public confidence in the vaccines, safety, and accelerates the vaccination process against COVID-19.

The results of this study will be reassuring to those who are fearful of the ASTRAZENECA COVID-19 vaccine. So, the goal of this study to provide evidence on ASTRAZENECA COVID vaccine side effects after receiving 1 st and 2 nd dose of it.

\section{Method}

An institutional based cross sectional survey was conducted at Nigist Elleni Mohamed specialized hospital (NEMMSH), from July 01/2021 to August 30/2021 at Nigist Elleni Mohamed Memorial specialized hospital found in Hossana town, the capital of Hadya zone, Ethiopia (Figure 1).

The required data were collected after obtaining ethical clearance from Wachemo University College of medicine and health science institutional review committee. Written informed consent form that included statements about voluntary participation and anonymity was sought from all the respondents prior to data collection. This was accomplished by sending a standardized general invitation letter with the survey link to accept or decline participation to those who took both dose of ASTRAZENECA COVID vaccine.

The participant who declined consent was not permitted to open the survey and participate in the study, and participants could withdraw from the survey at any time. The members who clicked on

\section{Duration of symptoms}

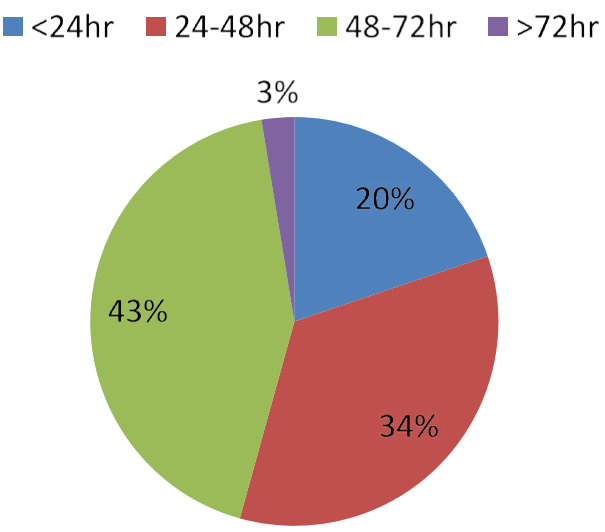

Figure 1: The duration of side effects of among NEMMSH health workers after first dose of ASTRAZENECA COVID vaccine from July 01/ 2021 to August 30/2021.

the link were directed to the Google forms and to avoid the missing data, the participants will be requested to fill all the questions of the survey or else could not proceed to the next section. No incentives or compensations have been given to participants.

The study employs a self-administered online survey created on Google Forms of platform which had been randomly delivered to NEMMSH health workers via (Facebook or telegram pages). Potential participants are directed to a page that included brief introduction to the aim and purpose of the study. Data were collected from all who took both dose of the vaccine and sent response during data collection period.

The survey will include two sections, the first section included demographic questions such as (gender, age, profession) second section reviewed the presence of participant's chronic conditions and ASTRAZENECA COVID-19 vaccine side effects (pain at the vaccination site, tenderness, redness, fever, headache, fatigue, nausea, diarrhoea, muscle pain, back pain). For pilot testing, a questionnaire was passed randomly to 15 participants recently vaccinated and filled the questionnaire after taking the two doses and have been excluded from the study.

The Statistical Package for the Social Sciences (SPSS) version 20.0 was used to carry out descriptive statistics for the demographic variable's similarly, chi square test analysis were performed to assess the correlation between the presence of vaccine side effects and demographic variables. The results were presented by using text, tables, charts and graph.

\section{Results}

\section{Demographic Characteristics of Participants}

A total of 261 responses were received from respondents. From the total number of responses 7 participants data was incomplete and totally 254 participants were included in the final analysis. 98 (38.6\%) were females, 156 (61.4\%) were males and the mean age of the respondents was $29.9 \pm 5.8$ years old with the median age of 28.5 . About 13 (5.1\%), 68 (26.8\%), 124 (48.8\%), 37 (14.6\%) and 12 (4.7\%) 
were Anaesthetists, Medical doctors, Nurse/Midwife, Pharmacy professional/Lab technicians and Public health experts, respectively. From the total participated health workers, 149 (59\%) have $\leq 5$ year of work experience and the rest of participants work experience was $>5$ years (Tables 1 and 2).

\section{Prevalence of Side Effects after First Dose Vaccine}

From the total number of respondents (254), 91.3\% (232) participants have reported at least one side effect after first dose of vaccine. Over all, injection site pain was the most prevalent side effect followed by headache (48.8\%), fever (38.8\%) and muscle pain (38.8\%). The prevalence of at least one side effect is slightly greater on males (93.5\% vs. $87.7 \%)$. At least one side effect among the younger age group ( $\leq 29$ year old) is nearly greater than participants whose age was $>29$ year old ( $94.4 \%$ vs $87.7 \%$, respectively).

\section{Onset and Duration of Side Effects after First Dose of Vaccine}

From the total number of respondents who experienced Side effect, $52.5 \%$ of them felt the side effect after $6 \mathrm{~h}$ of vaccination and followed by $26.7 \%$ (after 1 to $2 \mathrm{~h}$ ), $18 \%$ ( 3 to $5 \mathrm{~h}$ ), and $3 \%$ (immediately).

Table 1: Demographic characteristic of participants who took ASTRAZENECA covid vaccine from July 01/ 2021 to August 30/2021 in NEMMSH.

\begin{tabular}{|l|c|c|}
\hline Variables & Category & Frequency (\%) \\
\hline \multirow{3}{*}{ Sex } & Female & $98(38.6 \%)$ \\
\cline { 2 - 3 } & Male & $156(61.4 \%)$ \\
\hline \multirow{3}{*}{ Year of experience } & $\leq 29$ year old & $145(57 \%)$ \\
\cline { 2 - 3 } & $>29$ year old & $109(43 \%)$ \\
\hline \multirow{3}{*}{ Profession } & $\leq 5$ year & $149(59 \%)$ \\
\cline { 2 - 3 } & $>5$ year & $105(41 \%)$ \\
\cline { 2 - 3 } & Anaesthetist & $13(5.1 \%)$ \\
\cline { 2 - 3 } & Medical doctors & $68(26.8 \%)$ \\
\cline { 2 - 3 } & Pharmacy professionals/ Lab technician & $37(14.6 \%)$ \\
\cline { 2 - 3 } & Public health officer & $12(4.7 \%)$ \\
\hline
\end{tabular}

Table 2: The prevalence of side effects among NEMMSH health workers after first dose of ASTRAZENECA COVID vaccine from July 01/ 2021 to August 30/2021.

\begin{tabular}{|l|c|c|}
\hline \multirow{2}{*}{ Side effects } & \multicolumn{2}{|c|}{ Category } \\
\cline { 2 - 3 } & Yes & No \\
\hline Injection site pain & $162(63.8 \%)$ & $92(36.2 \%)$ \\
\hline Tenderness at the site & $70(27.6 \%)$ & $184(72.4 \%)$ \\
\hline Fever & $98(38.6 \%)$ & $156(61.4 \%)$ \\
\hline Muscle pain & $98(38.6 \%)$ & $156(61.4 \%)$ \\
\hline Fatigue & $66(26 \%)$ & $188(74 \%)$ \\
\hline Back pain & $52(20.5 \%)$ & $202(79.5 \%)$ \\
\hline Joint pain & $70(27.6 \%)$ & $184(72.4 \%)$ \\
\hline Diarrhoea & $14(5.5 \%)$ & $240(94.5 \%)$ \\
\hline Headache & $124(48.8 \%)$ & $130(51.2 \%)$ \\
\hline Nausea & $12(4.7 \%)$ & $242(95.3 \%)$ \\
\hline
\end{tabular}

\section{Prevalence of Side Effects after Second Dose Vaccine}

A total of $69.7 \%$ of participants reported to have at least one side effect after second dose of ASTRAZENECA COVID vaccine. From the rest of side effects, again injection site pain was the most reported symptom with the magnitude of $50.4 \%$ and followed by headache $33.5 \%$, fatigue $28.7 \%$, and tenderness at the site $21.7 \%$, fever $20.9 \%$ and joint pain $20.9 \%$. There was no difference on the prevalence of at least one side effect between participants whose age is $\leq 29$ year old and $>29$ year old (69.7\% vs. 69.7\%). Regarding sex, there was also no much difference on prevalence of at least one side effect between the two group's male and female (68.5\% vs. $71 \%$, respectively) (Tables 3 and 4 ).

\section{Onset and Duration of Side Effects after Second Dose of Vaccine}

From the total participants who has experienced at least one side effect, most of emerged after $6 \mathrm{~h}$ (39\%) of vaccination and followed by $35 \%$ (within 1 to $2 \mathrm{~h}$ ), $14.7 \%$ (within 3 to $5 \mathrm{~h}$ ) and $11.3 \%$ of them immediately. $54.3 \%$ of participants who experience at least one side effect didn't take any treatment measure for the symptoms and about $16.1 \%$ of respondents just took bed rest. $29.5 \%$ of participants took antipain to relieve the symptoms.

\section{The Correlation between Side Effects and Participant's Age}

After first dose of vaccine, the study finding reveals there is significant difference $(\mathrm{p}=0.04)$ between those who were under the age of 29 years and suffering from COVID-19 vaccine side effects and those over the age of 29. There was no significant difference between the two groups (Age $\leq 29$ vs. $>29$ ) on side effect reported after second dose of vaccine (Table 5).

Table 3: The prevalence of side effects among NEMMSH health workers after second dose of ASTRAZENECA COVID vaccine from July 01/ 2021 to August 30/2021.

\begin{tabular}{|l|c|c|}
\hline \multirow{2}{*}{ Side effects } & \multicolumn{2}{|c|}{ Category } \\
\cline { 2 - 3 } & Yes & No \\
\hline Injection site pain & $128(50.4 \%)$ & $126(40.6 \%)$ \\
\hline Tenderness at the site & $55(21.7 \%)$ & $199(78.3 \%)$ \\
\hline Fever & $53(20.9 \%)$ & $201(79.1 \%)$ \\
\hline Muscle pain & $55(21.7 \%)$ & $199(78.3 \%)$ \\
\hline Fatigue & $73(28.7 \%)$ & $181(71.3 \%)$ \\
\hline Back pain & $52(20.5 \%)$ & $202(79.5 \%)$ \\
\hline Joint pain & $53(20.9 \%)$ & $201(79.1 \%)$ \\
\hline Diarrhoea & $14(5.5 \%)$ & $240(94.5 \%)$ \\
\hline Headache & $85(33.5 \%)$ & $169(66.5 \%)$ \\
\hline Nausea & $22(8.7 \%)$ & $232(91.3 \%)$ \\
\hline
\end{tabular}

Table 4: The correlation of participant's age and side effect after first and second dose of ASTRAZENECA covid vaccine.

\begin{tabular}{|l|c|c|c|}
\hline & \multicolumn{2}{|c|}{ Frequency (\%) } & Chi-square \\
\cline { 2 - 4 } & Age $\leq 29($ year $)(\mathrm{n}=145)$ & Age $>29($ year $)(\mathrm{n}=109)$ & P value \\
\hline Side effect after $1^{\text {st }}$ dose & $137(94.4 \%)$ & $95(87.7 \%)$ & 0.04 \\
\hline Side effect after 2 ${ }^{\text {nd }}$ dose & $101(69.7 \%)$ & $76(69.7 \%)$ & 0.999 \\
\hline
\end{tabular}

Chi-squared test were used with a significance level of $<0.05$. 
Table 5: The correlation of participant's sex and side effect after first and second dose of ASTRAZENECA covid vaccine.

\begin{tabular}{|l|c|c|c|}
\hline \multirow{2}{*}{} & \multicolumn{2}{|c|}{ Frequency (\%) } & Chi-square \\
\cline { 2 - 4 } & Male $(\mathrm{n}=156)$ & Female $(\mathrm{n}=98)$ & P value \\
\hline Side effect after $1^{\text {st }}$ dose & $146(93.5 \%)$ & $86(87.7 \%)$ & 0.108 \\
\hline Side effect after $2^{\text {nd }}$ dose & $107(68.5 \%)$ & $70(71 \%)$ & 0.63 \\
\hline
\end{tabular}

Chi-squared test were used with a significance level of $<0.05$.

\section{The Correlation between Side Effects and Participant's Sex}

The study result demonstrates there were no significant differences in the number of female participants who reported side effects compared to males after both first and second dose of vaccine.

\section{Discussion}

Most of the studies assessed the adverse reaction of Pfizer, Moderna and BioNTech vaccines. There were no sufficient published studies done on side effect of ASTRAZENECA COVID vaccine. The first shipment of the AstraZeneca vaccines produced by Serum Institute of India (SII) arrived in Ethiopia on 6 March 2021.

Over all the finding of this study demonstrates the side effects of this vaccine appear to be mild. According to this study more than $90 \%$ of respondents have experienced side effect during the first shot. The prevalence of side effect during the second shot of vaccine was lower than the first dose (69.7\%), none of this symptoms are serious in nature and requires hospitalization. This result is in line with the cross-sectional survey-based study among German healthcare workers, the frequency of experiencing at least one side effect were $88.1 \%$ [13]. Another study conducted in India, $65.9 \%$ of respondents reported at least one post-vaccination symptom [14] cross sectional survey conducted on residents of Poland shows, Among those vaccinated with the first dose of the AstraZeneca vaccine, 96.5\% reported at least one post-vaccination reaction. $17.1 \%$ of respondents reported all the side effects listed in the survey $[15,16]$. The variation in prevalence might be related with unequal sample size or difference in demographic distribution.

According to our study finding, injection site pain was the most prevalent side effect during both first and second dose of vaccine $(63.8 \%$ vs. $50.4 \%)$ and followed by headache $(48.8 \%$ vs. $33.5 \%)$, fever $(38.8 \%$ vs. $20.9 \%)$, muscle pain $(38.8 \%$ vs. $21.7 \%)$, fatigue ( $26 \%$ vs. $28.7 \%$, tenderness at the site ( $27.6 \%$ vs. $21.7 \%$ ), and joint pain ( $27.6 \%$ vs. $20.9 \%)$. Injection of drug at contracted muscle leads to pain at the site. Injection site pain was reported by many studies to be the most frequent side effect of post vaccination. Cross sectional survey conducted in Czech Republic health workers demonstrates $89.8 \%$ of participants reported to have injection site pain and followed by fatigue (62.2\%), headache (45.6\%), muscle pain (37.1\%), and chills (33.9\%) [15]. Another study conducted on Saud Arabian inhabitant also reported the short term side effect after first and second dose of COVID vaccine. According to this study the most common symptoms were injection site pain, headaches, flu-like symptoms, fever, and tiredness. [17].

According to our study, most of respondent's side effects emerged after $6 \mathrm{~h}$ of vaccination during both first and second dose of COVID vaccine ( $52.5 \%$ vs. $39 \%$, respectively). Nearly quarter of respondents

\section{Duration of side effects}

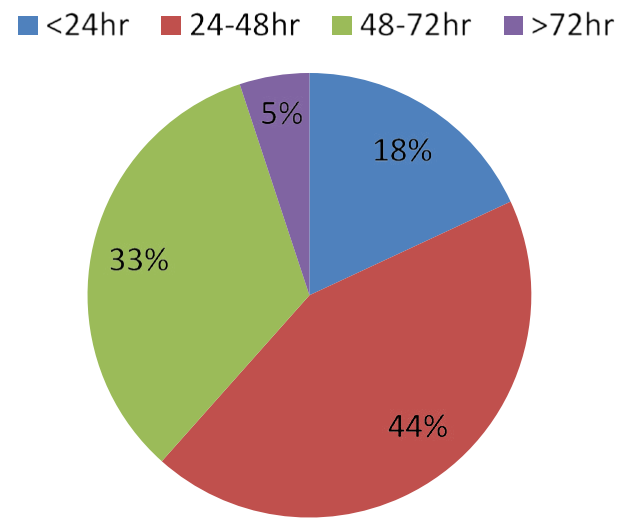

Figure 2: The duration of side effects of among NEMMSH health workers after second dose of ASTRAZENECA COVID vaccine from July 01/ 2021 to August 30/2021.

after first dose and 35\% of respondents after second dose reported the onset of symptom was after 1 to $2 \mathrm{~h}$ of post vaccination. Regarding the duration of symptoms, most of participants responded their symptoms disappeared with in the first 24 to $48 \mathrm{~h}$ of vaccination on both first and second dose of vaccine (44\% vs. $34 \%$, respectively) (Figure 2). Only $3 \%$ of respondent's symptoms after first dose and $5 \%$ of respondent's symptoms after second dose have lasted more than $72 \mathrm{~h}$ of post vaccination. This finding is in line with many of studies undergone to assess the side effect of COVID vaccine $[13,14,16,17]$.

In our study the younger age ( $\leq 29$ year) were more susceptible to at least one side effect $(\chi 2=4.2 ; \mathrm{p}=0.04)$ after first dose of ASTRAZENECA COVID vaccine. This result is in line with a study done to assess the side effect of COVID vaccine among German health workers [13] and another Cross sectional survey undergone among individuals in UAE [18]. However difference in terms of side effect between male and female were not statistically significant after both first and second dose vaccine.

\section{Strength and Limitation of the Study}

The finding of this study should be interpreted cautiously regarding the external validity since sex and profession of participants are not equally distributed. The data was collected online through Google form so that only respondents who are motivated will fill and submit the questions which might result for selection bias. Data were collected from health workers who have good understanding about the nature of items, so the outcome were expected to be reported correctly. The data were self-reported which strengthen its objectivity. To the best of our knowledge, this is the first study conducted to assess the side effect of ASTRAZENECA COVID vaccine among health workers resource limited setting.

\section{Conclusion}

The prevalence of side effect after first and second dose vaccine was higher. Most of the symptoms were short lived, mild and doesn't require hospitalization. This result might help to solve an emerging public health challenge (vaccine hesitancy) nurtured by misinformation related to vaccines safety. 


\section{Ethics Approval and Consent to Participate}

The required data were collected after obtaining ethical clearance from Wachemo University College of medicine and health science institutional review committee. In addition permission from both health institutions and written consent from each participant was obtained.

\section{Acknowledgements}

This work is dedicated to thousands of fatalities and their families who have fallen victim to COVID-19 in Ethiopia. The authors would also like thank respondents who gave their time to fill and submit the questioner.

\section{References}

1. El-Sahly HM, Atmar RL, Glezen WP, et al. (2000) Spectrum of clinical illness in hospitalized patients with "common cold" virus infections. Clinl Infect Dis 31: 96100. [crossref]

2. Kaur A, Bhalla V, Salahuddin M, Rahman SO, Pottoo FH (2021) COVID -19 infection: Epidemiology, Virology, Clinical Features, Diagnosis and Pharmacological Treatment. Curr Pharm Des.

3. National Center for Immunization and Respiratory Diseases (NCIRD), Division of Viral Diseases. CDC COVID-19 Science Briefs [Internet]. Atlanta (GA): Centers for Disease Control and Prevention (US); 2020-. Scientific Brief: SARS-CoV-2 Transmission. [Updated 2021 May 7].

4. Lu R, Zhao X, Li J, et al, (2020) Genomic characterisation and epidemiology of 2019 novel coronavirus: implications for virus origins and receptor binding. Lancet 395 : 565-574.

5. Rothan HA, Byrareddy SN (2020) The epidemiology and pathogenesis of coronavirus disease (COVID-19) outbreak. J Autoimmun 109: 102433. [crossref]

6. Guo Y-R, Cao Q-D, Hong Z-S, Tan YY, Chen SD, et al. (2020) The origin, transmission and clinical therapies on coronavirus disease 2019 (COVID-19) outbreak - an update on the status. Mil Med Res 7: 11. [crossref]

7. Coleman CM, Frieman MB (2014) Coronaviruses: important emerging human pathogens. J Virol 88: 5209-5212. [crossref]

8. Haidere M, Ratan Z, Nowroz S, Zaman S, Jung Y, et al. (2021) COVID-19 Vaccine: Critical Questions with Complicated Answers. Biomolecules \& Therapeutics 29: 1-10. [crossref]

9. Medicine and health care regulatory agency, Regulation 174 Information for UK healthcare professionals, sept, 2021.

10. Norweighan medicine agency, Reported suspected adverse reactions to coronavirus vaccine, 2021.

11. Dror AA, Eisenbach N, Taiber S, Morozov NG, Mizrachi M, et al. (2020) Vaccine hesitancy: The next challenge in the fight against COVID-19. Eur J Epidemiol 35: 775-779.

12. Szmyd B, Karuga FF, Bartoszek A, Staniecka K, Siwecka N, et al. (2021) Attitude and Behaviors towards SARS-CoV-2 Vaccination among Healthcare Workers: A CrossSectional Study from Poland. Vaccines 9: 218. [crossref]

13. Klugar M, Riad A, Mekhemar M, Conrad J, Buchbender M, et al. (2021) Side Effects of mRNA-Based and Viral Vector-Based COVID-19 Vaccines among German Healthcare Workers. Biology (Basel) 10: 752. [crossref]

14. Dr Rajeev Jayadevan, Dr Ramesh Shenoy, Ms. Anithadevi TS (2021) Survey of symptoms following COVID-19 vaccination in India, medRxiv.

15. Riad A, Pokorná A, Attia S, Klugarová J, Koš cík M, et al. (2021) Prevalence of COVID19 Vaccine Side Effects among Healthcare Workers in the Czech Republic. J Clin Med 10: 1428.

16. Andrzejczak-Grządko S, Czudy Z, Donderska M (2021) Side effects after COVID-19 vaccinations among residents of Poland. Eur Rev Med Pharmacol Sci 25: 4418-4421. [crossref]
17. I-Shitany NA, Harakeh S, Badr-Eldin SM, Bagher AM, et al. (2021) Minor to Moderate Side Effects of Pfizer-BioNTech COVID-19 Vaccine Among Saudi Residents: A Retrospective Cross-Sectional Study. Int J Gen Med 14: 1389-1401. [crossref]

18. Saeed BQ, Al-Shahrabi R, Alhaj SS, Alkokhardi ZM, Adrees AO (2021) Side effects and perceptions following Sinopharm COVID-19 vaccination. Int J Infect Dis 111: 219-226. [crossref]

\section{Citation:}

Garoma G, Tamrat H, Shitemaw T, Desalegn M (2021) The Prevalence of ASTRAZENECA COVID Vaccine Side Effects among Nigist Elleni Mohamed Memorial Specialized Hospital Health Workers: Cross Sectional Survey. Integr J Anesth Sur Volume 2(2): 1-5. 